\title{
LITERATURA E PERFORMANCE
}

Juliana Helena Gomes Leal

Doutora em Literatura Comparada do Programa de Pós-Graduação em Estudos Literários /

UFMG

\begin{abstract}
RESUMO
Este artigo objetiva apresentar a perspectiva teórico-crítica delineada em minha tese de doutoramento defendida pelo Programa de Estudos Literários da Faculdade de Letras da Universidade Federal de Minas Gerais, orientada pela professora Graciela Ravetti e cuja temática versou sobre a relação entre o texto literário em prosa e a performance.
\end{abstract}

\section{PALAVRAS-CHAVE}

Performance, literatura, escrita performática

Pensar a literatura em diálogo com os estudos da performance tem sido uma das vias para o exercício de compreensão de certas narrativas que se apropriam do corpo ou que constroem textualizações vinculadas ao corpóreo cujo viés experimental se faz normalmente presente e que se mostraram ou vêm se mostrando avessas ou resistentes a teorizações conservadoras e hierárquicas, pautadas, frequentemente, numa perspectiva estruturalista reticente em assumir a escrita como experiência, por vinculá-la apenas dentro de uma cultura da normatividade. ${ }^{1}$

Mas apesar da desconfiança e descrença que ainda persistem no estabelecimento dessa relação, o número de pesquisas que se debruçam para pensar o estatuto da escrita literária a partir do viés da performance aumenta a cada dia, o que acaba sacudindo e, consequentemente, reacomodando o quadro epistemológico a partir do qual o conceito de literário se movimenta, embaralhando os discursos mais certeiros sobre tradição. Isso abriria espaço para perspectivas culturais mais heterogêneas e revolucionárias, se recupero Rancière (2005, 2009), para pensar o estatuto da literatura enquanto arte potencialmente representável

\footnotetext{
${ }^{1}$ BEIGUI. Performances da escrita, p. 29.
} 
por diferentes formas de visibilidade e pensabilidade artísticas. E, também, para reflexão do literário, que é compreendido e construído por meio da inclusão produtiva dos opostos e dos contraditórios, que considera o ínfimo e o banal como substâncias produtivas para a Arte e que dá abertura para o que se encontra à margem ou fora do padrão social e do modelo estético. Enfim, uma estética que revela uma postura crítica em relação à visão hegemônica de representação do mundo.

“[P]or resistir tanto a uma única classificação”, ${ }^{2}$ afirma Regina Melim, é que o termo “performance” me parece adequado para ler uma série de obras literárias que têm escapado ao rolo censor das rotulações, sendo usado como chave teórica ou lente metodológica na abordagem da teoria e da crítica literária por vários estudiosos, entre os quais estão variados pesquisadores que integram o Núcleo de Artes Performáticas (NELAP) ${ }^{3}$ da Faculdade de Letras da Universidade Federal de Minas Gerais.

Talvez, ditas desconfiança e descrença sobre o esforço empreendido em aproximar a literatura da performance, residam no fato de que uma materialidade visível aos olhos - a do corpo do artista - esteja quase sempre presente na conformação final de obras com o qualificativo performático: um texto espetacular, a execução de uma composição musical ou a realização de um espetáculo de dança, por exemplo, porque, na maior parte das vezes, falar de performance como evento é pensar no ao vivo e/ou no in loco da experiência da cena artística, o que, segundo Regina Melim, sustenta “o estereótipo que associa a noção de "performance” a um único formato”. ${ }^{4}$ Não raro é relacionar, especialmente a partir do surgimento da bodyart, nos anos 1960, movimento artístico que deslocava o ponto focal do produto para o processo, da obra para o criador, a utilização do corpo como parte constitutiva da obra, como suporte artístico, levando-nos “a pensar em um único formato [para as artes performáticas],

\footnotetext{
${ }^{2}$ MELIM. Performance nas artes visuais, p. 7.

${ }^{3}$ As professoras Sara del Carmen Rojo de la Rosa e Tereza Virgínia Ribeiro Barbosa coordenam, atualmente, o Núcleo de Estudos em Letras e Artes Performáticas (NELAP) da FALE/UFMG, grupo de pesquisa registrado no $\mathrm{CNPq}$ desde 1999, do qual fazem parte artistas e inúmeros pesquisadores, entre professores e alunos de graduação e pós-graduação de diferentes áreas do conhecimento, que se dedicam a investigações individuais ou projetos coletivos em 4 (quatro) linhas de pesquisa, a saber: 1. Literatura e Expressão da Alteridade; Literatura e Outros Sistemas Semióticos; Literatura, História e Memória Cultural; e Texto e Performance. O NELAP tem como objetivo central ser um espaço de reflexão teórica e realização de atividades práticas concernentes às relações intersemióticas entre as Letras e as Artes Performáticas (Teatro, Cinema, Artes Visuais, Vídeo, Música, Dança), entre outros objetivos. Para mais informações, acessar: $<$ www.letras.ufmg.br/nelap>.

${ }^{4}$ MELIM. Performance nas artes visuais, p. 8.
} 
baseado no artista em uma ação ao vivo, visto por um público, num tempo e espaço específicos". 5

Por se tratar de uma postura metodológica, uma práxis do pensamento crítico aberta à leitura de um campo incerto, inarmônico, movediço, contraditório, desconexo como normalmente o é o da escrita performática, menos preocupada "com a literariedade do texto e mais com o projeto de experimentação da escrita em jogo”, 6 menos inclinada a situar-se no sólido campo da objetividade que a lançar-se como camicase no universo do desconhecido, do inominável e do inclassificável, vejo a necessidade e a consequente produtividade de se pensar o literário pela via da performance.

Por que não qualificar como material também aquilo que sobrevive em nós como rastro indelével, como sensação etérea, como percepção fugidia? E como encarcerar as implicações de uma materialidade como essa apenas na esfera do estático, do visível, do delimitável, se o performático é fundamentalmente ação, movimento, fluxo, “ato dentro de uma imagem”, “fazer corporal”? ${ }^{7}$ Na esteira disso é que Guillermo Gómez-Peña define a arte da performance como “um ‘território’ conceitual com clima caprichoso e fronteiras mutáveis; um lugar onde a contradição, a ambiguidade e o paradoxo não são tolerados, mas estimulados". 8

Assim, refletir sobre o conceito de escrita-corpo ou escrita encarnada não nos é senão o transbordamento em outras esferas artísticas, como na escrita literária performática, da presença do corpóreo que potencializa a força do verbo que experimenta, muitas vezes, aquilo que não é. ${ }^{9}$ A concepção de escrita performática se pautaria, nesse sentido, a partir da noção de corpo desmaterializado, isto é, o corpo-vestígio, o corpo-relação, do que da ideia de corpo como suporte, como uma instância dotada apenas de uma possibilidade de formato, aquele normalmente relacionado à estabilidade e à visibilidade.

\footnotetext{
${ }^{5}$ MELIM. Performance nas artes visuais, p. 7.

${ }^{6}$ BEIGUI. Performances da escrita, p. 31.

${ }^{7}$ RAVETTI. Performances escritas: o diáfano e o opaco da experiência.

8 “un 'territorio' conceptual con clima caprichoso y fronteras cambiantes; un lugar donde la contradicción, la ambigüedad, y la paradoja no son sólo toleradas, sino estimuladas” (GÓMEZPEÑA. En defensa del arte del performance, p. 203, tradução minha).

${ }^{9}$ Refletir sobre as implicações de uma aproximação entre a arte da performance e a literatura, diante do exposto acima, é concordar com a crítica que fez Jorge Glusberg ao postulado L'art pou l'art, que não admitia, segundo ele, a interferência de um suporte artístico no outro, negando a possibilidade de que "uma mídia pode, de fato, ser interessante e desafiadora quando tenta algo QUE ELA NÃO É” (GLUSBERG. A arte da performance, p. 142, maiúsculas no original).
} 
Dessa visão decorreriam, para Renato Cohen, os fundamentos da definição de "performance” como uma linguagem de experimentação artística que, ao se inclinar a uma aproximação mais estreita com a vida, se esquivaria de representá-la. Lançar-se-ia, ao contrário, à prática ou ao exercício de ressignificação e releitura do mundo a partir do uso livre e desierarquizado de uma multiplicidade de códigos artísticos. Daí a escrita literária performática ser entendida a partir da concepção de Cohen, que compreende a performance como uma arte de fronteira, que, escapando a delimitações conceituais, por seu caráter eminentemente anticonvencionalista e antinaturalista, cria um topos de experimentação por incorporar simultaneamente elementos de expressões consideradas artísticas e não artísticas. ${ }^{10}$ Como consequência disso, o real seria reelaborado e a obra de arte ganharia consistência ontológica própria, o que forçaria o envolvimento da audiência na elaboração de sentidos e textualizações para aquilo que, num primeiro momento, transitaria para ela apenas no âmbito do sensitivo e do emotivo por ser experiência estética de natureza mítica, uma vivência do real, ${ }^{11}$ nos termos de Cohen.

A perspectivação articulatória e agregadora, traço multifuncional, que o termo “performance” traz consigo dá abertura para a construção de uma crítica estimulante para leitura de um tipo de experiência literária que costuma tomar emprestado, reler, testar e se atrever a fazer uso das particularidades da dimensão orgânica e pulsátil do corpo como forma de subverter o disciplinar, de romper com as convenções narrativas (tanto no que se refere à substância como matéria literária, quanto às formas de organização desse material na estrutura composicional da obra).

Essa dimensão plurissensorial, incitada pelas idiossincrasias do corpóreo inerente às artes performáticas, impulsiona um distanciamento do racional que favorece a realização de uma experiência cognitivo-intelectual da ordem do sensitivo e do perceptivo. Uma ordem que não é só experenciada pelo propositor do objeto ou da ação artística, mas pelo participante que se insere no acontecimento/experiência da arte, modificando-a por sua presença e modificando-se em razão de sua existência; mesmo que esse processo se dê numa perspectiva

\footnotetext{
${ }^{10}$ COHEN. Performance como linguagem, p. 139-140.

${ }^{11}$ Para discorrer sobre a expressão vivência do real, Renato Cohen diferencia dois tipos de relação que podem surgir na estruturação da arte cênica. A primeira, denominada relação estética e a outra, relação mítica. Na primeira, haveria, entre a instância criadora e a recepção, um distanciamento advindo das posições que a criação e a recepção tomam para si, ao passo que na segunda esse distanciamento seria eliminado em razão da participação dupla do agente da criação e da recepção na obra. Daí ele afirmar que: "na relação estética existe uma representação do real e na relação mítica uma vivência do real” (COHEN. Performance como linguagem, p. 122).
} 
da estranheza, do embate, do conflito e do desconforto, lugar onde habitualmente se localiza o confronto visceral com o universo apresentado pela alteridade.

Desse modo é que os significados que despontam no cenário acadêmico sobre o conceito de escrita literária performática acabam fortalecendo sua existência oferecendo a esse operador teórico vitalidade para se manter cada dia mais digno da atenção e da reflexão continuada dos investigadores que se solidarizam com ele. Atitude que transforma, se me apoio novamente em Rancière, não só o cenário geral a partir do qual essas práticas artísticas (seus modos de fazer ou seus fazeres) são vistas, mas a própria configuração formal e conceitual (seu ser) dessas práticas. Daí Daniel Link ${ }^{12}$ chamar a atenção para a necessidade da análise crítica de todo o sistema classificatório normatizador interposta pelo desafio que a arte e a literatura experimentais, incluindo os textos literários, que, tomados como organismos vivos performam, têm apresentado para os que se dedicam aos estudos literários.

Foi por essa razão que decidi tentar aprofundar, em minha tese de doutorado, intitulada Literatura e performance: incursões teóricas a partir da escrita literária de Lemebel, Lispector, Prata e Saer, a discussão teórica acerca da relação entre literatura e performance - compreendendo o termo “escrita performática” como chave teórica de análise da produção literária de distintos contextos, por acreditar que o performático poderia (e pode) ser encontrado em obras de gêneros variados e de distintas escolas históricas. Crença que não restringe sua abordagem apenas à leitura crítica de textos literários contemporâneos, tornando-se, assim, uma opção crítica que lê um corpus e se constitui como uma poética da leitura que reconhece uma poética da escrita adjetivada como performática.

Compreendida como conceito, a "performance" pode ser identificada, defende Denise Pedrón, a despeito do gênero artístico, já que possui vocação interdisciplinar, “mobilidade e ampla capacidade de disseminação nos diversos campos da arte”. ${ }^{13}$ Daí meu interesse pelo diálogo entre a performance e a literatura para atender a uma disposição cognitivo-intelectual que permitisse revelar e desenvolver possibilidades de significação que certos textos literários possuem em latência ou até mesmo explicitamente desenvolvidas, tais como os que analisei em minha tese. A saber: os romances A hora da estrela, de Clarice Lispector, e Nadie nada nunca, de Juan José Saer, e livros de crônicas dos escritores Pedro Lemebel e Antonio Prata, respectivamente: Adiós mariquita linda, As pernas da tia Corália, Douglas e outras histórias, Estive pensando, Meio intelectual, meio de esquerda e O inferno atrás da pia.

\footnotetext{
${ }^{12}$ LINK. Clases, literatura y disidencia, p. 19.

${ }^{13}$ PEDRON. Um olhar sobre a performatividade na cultura contemporânea: a performance como conceito e a produção artística de Diamela Eltit, p. 153.
} 
A escolha dos já canonizados Clarice Lispector e Juan José Saer e dos escritores pouco ou ainda não estudados - Antônio Prata e Pedro Lemebel, autores de diferentes países e lugares específicos de enunciação cujas publicações aconteceram em diferentes momentos Clarice, ao final da década de 1970 (Brasil); Saer (argentino na França), no início da de 1980, e os outros dois autores ao longo da primeira década do século 21: Lemebel (Chile) e Prata (Brasil) - se deveu à tentativa de sinalizar a heterogeneidade espaçotemporal a partir da qual os textos performáticos são e podem ser gestados.

Minha hipótese de trabalho em minha pesquisa de doutoramento partiu de um levantamento não exaustivo do termo “performance”, como arte e como conceito, buscando aproximá-lo dos Estudos Literários, de modo a encontrar pontos de contato produtivos para refletir sobre o operador "escrita performática”. Entre esses pontos de contato, foi possível perceber, de início, ao menos três: a presença de um caráter relacional e comunicacional subjacente às manifestações ou aos produtos artísticos pautados na performance; uma dimensão corpórea identificável nessas criações; e o movimento transgressor, dissidente ou experimental perceptível na forma e/ou no conteúdo dessas manifestações.

No romance A hora da estrela, essa ruptura se daria a partir de um movimento transgressor dos limites entre as instâncias ficcionais (narrador/personagem e imagem de leitor), que se inclina a construir uma espacialidade ou atmosfera polifônica que potencializa o surgimento de outras textualidades. O performático como instância ou qualificativo agregador da alteridade, via palavra.

Pensado assim, o narrador performático seria mais do que um elemento da narrativa, mas Uma instância ficcional que narra porque vivencia a narração. Ao narrar o outro, narra a si próprio. Ao narrar o outro e a si mesmo, demanda, simultaneamente, uma narração semelhante por parte da imagem de leitor que se inscreve nas linhas da estrutura narrativa da obra. Um leitor que será convocado a "sair de si para ver o outro", ${ }^{14}$ assim como o faz o narrador do romance clariciano, que, durante toda a obra, faz questão de enfatizar as rasuras nos limites entre o eu (ele) e o outro (Macabéa), desnudando a dimensão comunicacional e relacional vinculada, em minha pesquisa, ao qualificativo performático da escrita literária.

Narrar performaticamente é narrar o si-mesmo também a partir de um fora, do outro, do exo e situado numa localidade propositiva, cuja força reside nos meandros não delimitáveis do "mais além” interposto pelo transgênero performático. Esse narrador não se coloca em uma posição de conselheiro, nem de alguém autorizado a transmitir, exemplarmente, saberes

\footnotetext{
${ }^{14}$ LISPECTOR. A hora da estrela, p. 30.
} 
ou fatos a outrem. Vemos, ao contrário, um narrador aberto à experiência enriquecedora e humana da alteridade, para construir uma narração de um real que lhe escapa todo o tempo, porque a relação entre quem narra e o objeto do relato transfigura aquele continuamente, transformando a possibilidade da apreensão de uma história apenas a ser transmitida em algo inviável, o que leva esse narrador a qualificar essa personagem para além do que suporia nomeá-la como “objeto”.

No romance Nadie nada nunca, de Juan José Saer, percebemos que o caráter errático da escrita saeriana resiste à lógica dos enredos e da representabilidade tradicional, porque se dispõe mais à ação e aos domínios sensitivos do que às interpretações e aos produtos. Ademais, está inclinada a se apropriar da heterogeneidade dos diferentes sistemas de representação capazes de ampliar e intensificar as fronteiras da percepção, por se deslocarem pelos meandros do instável, do provisório, bem como para dar conta daquilo que sempre nos escapa, do qual é impossível uma apreensão completa. O resultado disso é o surgimento de outras formas de inteligibilidade do texto literário resistente ao modelo aristotélico de causa e efeito ou à monologia de um sistema único de pensabilidade e de visibilidade artística, nos termos de Rancière, que revoga a política antagônica inerente à lógica representativa, cuja organização é quase sempre hierárquica e opositiva. As similaridades entre as propostas teóricas de Rancière e o que defendi em minha tese sobre performance descansam sobre o pilar experimental e errático da escrita performática, que rechaça situar-se dentro do padrão das "narrativas explicativas e semantizadas, que estabelecem sentidos fixos, anuladores das incertezas". 15

Assim, será possível identificar, nesse romance, um movimento descritivo orgânico, portanto, performático, propulsado por uma partilha de regimes representativos que dilatam e contraem a narração, visando dar conta da multiplicidade das formas com que os objetos e os seres, também em movimento, se encontram dispostos na natureza. Do work in progress do mundo. Daí a nítida sensação de que o romance de Saer não se presta à representação de imagens congeladas, mas à própria dinâmica da vida, feita de recuos, dispersões, variações, repetições incessantes e prolongamentos excessivos - acolhedor dos distintos fluxos das intensidades representativas. Esse regime escritural heterogêneo, presente no romance saeriano, se irmana com o performático, na medida em que também é receptivo ao vaguear inquietante dos fluxos criativos que deslocam e ampliam as fronteiras da percepção. Talvez

\footnotetext{
${ }^{15}$ RAVETTI. Nem pedra na pedra, nem ar no ar: reflexões sobre literatura latino-americana, p. 31.
} 
por essa razão, o enredo, ${ }^{16}$ traço marcante do romance moderno, seja, nessa obra, o que há de menos relevante, já que ela se centra muito mais na explicitação do trabalhoso exercício da construção de sua própria engrenagem, como se quisesse desdobrá-la ao infinito, em busca da revelação de seus mais recônditos vieses, do que na ancoragem do relato de temas.

Na abordagem das obras de Pedro Lemebel e Antonio Prata, levo em consideração o posicionamento teórico que considera que uma escrita literária seria performática na medida em que também nascesse e se desenvolvesse "como um híbrido, ou pela mistura de gêneros, de suportes, de conteúdos”17 e na medida em que deixasse transparecer na materialidade literária “a exposição radical do si-mesmo do sujeito enunciador assim como do local da enunciação", ${ }^{18}$ implicando uma "contaminação (contágio) entre todas as partes envolvidas e a consequente modificação dos agentes participantes", ${ }^{19}$ a partir de "um ato de leitura que seja, também, individual e coletivo, intransferível e intransitivo, permitindo estabelecer comunicações ainda que sejam somente instantes comunicativos”. ${ }^{20}$

Uma linguagem literária dessa natureza, que opera em um nível de risco e experimentação, potencializa as esferas das relações, porque “o consignante compromete seu corpo ou sua mirada (que é também seu corpo) e se projeta naquilo que executa”, ${ }^{21}$ levando o leitor, numa atitude responsiva, a performativizar subjetividades, implicando seu olhar, portanto, seu corpo, no diálogo inter-relacional instaurado entre o texto e ele. Modo de sociabilidade que viabilizaria a formação de redes intersubjetivas de enunciação que

${ }^{16}$ De qualquer modo, vale recuperar o esforço de síntese que fez Julián Fuks para explicitar o “enredo” do romance de Saer: "o que se conta, essencialmente, são os estados sucessivos dos corpos e das coisas dentro de uma determinada casa costeira e em seus arredores, ao longo de pouco mais de três dias. Há nela um escrutínio pormenorizado das infinitas nuances e variações da realidade tal como percebida pelos narradores que se revezam, todos se valendo de uma extrema distensão das descrições” (FUKS. Juan José Saer e o paradoxo necessário: ou uma poética da (i)mobilidade em Nadie nada nunca, p. 26).

${ }^{17}$ RAVETTI. Narrativas performáticas, p. 57.

18 RAVETTI. Narrativas performáticas, p. 47. Percebo esse movimento de “radicalização" na exposição do lugar enunciativo autoral nas capas de muitas obras do escritor chileno Pedro Lemebel. Para compreender esse procedimento, recorro a Michaud: “o corpo 'fim de século' é de agora em diante ao mesmo tempo sujeito e objeto do ato artístico. Torna-se onipresente onipresente nas imagens fotográficas e no vídeo. A partir dos anos $1990,80 \%$, ou até $90 \%$ da arte tomam o corpo como objeto. Quando não o mostra, utiliza-o sob a espécie do corpo do artista produtor e performer, tendo-se tornado, ele mesmo, obra e marca bem mais que criador de obras" (MICHAUD. Visualizações: o corpo e as artes visuais, p. 562-563).

${ }^{19}$ MICHAUD. Visualizações: o corpo e as artes visuais, p. 57.

${ }^{20}$ MICHAUD. Visualizações: o corpo e as artes visuais, p. 62.

${ }^{21}$ RAVETTI. O corpo na letra: o transgênero performático, p. 86. 
possibilitariam a construção de narrativas a partir das quais se possa identificar a "exposição" de experiências.

Essa lógica relacional presente na dinâmica estética da escrita performática das últimas décadas, como as de Prata e Lemebel, busca, portanto, a partir de variados estímulos (humor, afronta, sátira, etc.), criar uma rede discursiva viva, uma rede fluida de discursividades, porque se funda em deslocamentos de centros que, ora terá o centro localizado no texto impresso na página, ora nos textos que vão sendo formulados, pelo leitor, durante o processo de leitura. Emergências de subjetividades que não são somente a razão de ser da escrita literária, mas a razão da implicação, também corpórea, que os leitores têm diante delas por serem "tão contundente[s] que absorve[m] a mirada de quem o especta", ${ }^{22}$

A performance na letra de Lemebel e Prata costuma construir uma poética das coisas mais inusitadas, a partir da exploração de uma potência narrativa de imagens, elementos, temas, em princípio, imprevisíveis, configurando uma tendência literária que caminha na contramão da que opta por um engessamento interpretativo do material ou pelo uso recorrente de um locus semântico predeterminado: meio lícito de evitar o esgotamento dos sentidos atribuídos às coisas por meio de clichês semânticos.

Essa lógica de sustentabilidade, que resulta do deslocamento da leitura interpretativa habitualmente dada a certos objetos do cotidiano, confere outras possibilidades interpretativas, ainda que sejam, em sua maioria, inusitadas e descabeladas, resultando na formação de textos que realizam uma espécie de “desencontro da palavra com a ideia, que ofereceria ao leitor a possibilidade de um novo aprendizado das coisas”. ${ }^{23}$ Essa postura diante dos objetos e das coisas, que busca, neles, novos sentidos, ainda que vá à contramão de uma demanda por significações prontas, parece ser um meio lícito para simbolizar esse turbilhão multirreferencial que experenciamos na contemporaneidade a partir da prática do exercício livre da imaginação. Mas não de uma imaginação louca, como muitos a rotulam, mas de outra, que "des-razoa”.

A escrita performática, tomada assim, tem o caráter de problema de conhecimento, por abrir para questões ainda não sistematizadas e que, ao que parece, nunca o serão. Tentar colocar a performance - especialmente a escrita performática ou a performance escrita - em patamares de teoria abstrata, nos moldes de definições e descrições inclusivas, não é o melhor caminho para se pensar a performance. A força de postulação, de persuasão e de elaboração

\footnotetext{
${ }^{22}$ RAVETTI. Performances escritas: o diáfano e o opaco da experiência, p. 32, grifo da autora.

${ }^{23}$ Expressões usadas por Adalberto Muller Júnior na orelha da obra Matéria de poesia, de Manoel de Barros.
} 
que a performance escrita tem não pode ser apreendida, a não ser em seus próprios termos. É possível estabelecer diálogos teóricos, que foi a proposta de minha tese; mas não é um tratamento de filosofia positivista que vai dar conta da proteiformidade dessa noção. Uma noção que, como se pode perceber, resiste ao fechamento dos sistemas de classificação artísticos, por ser adepta ao trânsito e à partilha do sensível entre as diferentes formas de visibilidade estética. Abre-se, portanto, ao marginal, ao residual, ao aparentemente insignificante entre os símbolos da vida cotidiana, lançando-se ou em direção a uma experiência estética radicalmente vivencial que promova a emergência de subjetividades nos meandros da alteridade ou a outra, cujas organicidade e corporeidade resultam das forças ambíguas e heterogêneas inerentes ao texto performático que implodem, também, os supostos limites do literário.

Atribuir, portanto, relevância aos estudos da "performance” como conceito e como arte para a reflexão sobre o estatuto de certos textos literários estimula e alimenta um tipo de crítica que, antes de traçar critérios prévios definidores do literário, dá abertura para que os próprios textos sinalizem os percursos teóricos, culturais e artísticos que vão delineando em suas materialidades. Essa não costuma ser a estratégia mais usual de leitura teórico-crítica do literário, mas, se partimos da reflexão de Rancière, quando diz que "as práticas artísticas são 'maneiras de fazer' que intervêm na distribuição geral das maneiras de fazer e nas suas relações com maneiras de ser e formas de visibilidade”, ${ }^{24}$ somos mais ou menos levados a admitir a necessidade de uma redistribuição revitalizadora também nas formas de ler e interpretar o literário. E partir da performance, acredito, seria uma dessas vias.

\section{REsumen}

Este artículo busca presentar la perspectiva teórico-crítica construída en mi tesis defendida por el Programa de Estudios Literarios de la Facultad de Letras de la Universidade Federal de Minas Gerais, orientada por Graciela Ravetti, cuya temática se asenta sobre la relación entre el texto literario en prosa y la performance.

\section{PaLABRAs-CLAVE}

Performance, literatura, escritura performática

\footnotetext{
${ }^{24}$ RANCIÈRE. A partilha do sensível: estética e política, p. 17.
} 


\section{REFERÊNCIAS}

BARROS, Manoel de. Matéria de poesia. 6. ed. Rio de Janeiro: Record, 2007.

BEIGUI, Alex. Performances da escrita. Aletria: Revista de Estudos de Literatura, Belo Horizonte, v. 21 n. 1, p. 27-36, jan./abr. 2011.

FUKS, Julián Miguel Barbero. Juan José Saer e o paradoxo necessário: ou Uma poética da (i)mobilidade em Nadie nada nunca, 2009. 89p. Dissertação (Mestrado em Letras) Faculdade de Filosofia, Letras e Ciências Humanas, Universidade de São Paulo - USP, São Paulo, 2009.

COHEN, Renato. Performance como linguagem. São Paulo: Perspectiva, 2004.

GLUSBERG, Jorge. A arte da performance. Trad. Renato Cohen. São Paulo: Perspectiva, 2005.

GÓMEZ-PEÑA, Guillermo. En defensa del arte del performance. Revista Horizonte Antropológico, Porto Alegre, v. 11, n. 24, p. 199-226, jul./dez., 2005. Disponível em: $<$ http://www.scielo.br/scielo.php?pid=S0104-71832005000200010\&script=sci_arttext>.

Acesso em: 8 fev. 2011.

LEAL, Juliana Helena Gomes. La esquina es mi corazón: espacialidades performáticas nas crônicas de Pedro Lemebel. 2007. 149p. Dissertação (Mestrado em Estudos Literários) Faculdade de Letras, Universidade Federal de Minas Gerais, Belo Horizonte, 2007.

LEAL, Juliana Helena Gomes. Literatura e performance: incursões teóricas a partir da escrita literária de Lemebel, Lispector, Prata e Saer. 2012. 174p Tese (Doutorado em Estudos Literários) - Faculdade de Letras, Universidade Federal de Minas Gerais, Belo Horizonte, 2012.

LEMEBEL, Pedro. Adiós mariquita linda. Barcelona: Mandadori, 2006.

LINK, Daniel. Clases, literatura y disidencia. Buenos Aires: Grupo Editorial Norma, 2005.

LISPECTOR, Clarice. A hora da estrela. Rio de Janeiro: Rocco, 1998.

MELIM, Regina. Performance nas artes visuais. Rio de Janeiro: Jorge Zahar, 2008.

MICHAUD, Yves. Visualizações: o corpo e as artes visuais. In: CORBIN, Alain; COURTINE, Jean-Jacques; VIGARELLO, Georges (Org.). História do corpo: as mutações do olhar: o século XX. Trad. Ephraim Ferreira Alves. Petrópolis: Vozes, 2008. p. 541-565. v. 3.

PRATA, Antonio. Douglas e outras histórias. Rio de Janeiro: Azougue Editorial, 2001.

PRATA, Antonio. As pernas da tia Corália. Rio de Janeiro: Objetiva, 2003a.

PRATA, Antonio. Estive pensando: crônicas de Antônio Prata. São Paulo: Marco Zero, 2003b.

PRATA, Antonio. O inferno atrás da pia. Rio de Janeiro: Objetiva, 2004.

PRATA, Antonio. Meio intelectual, meio de esquerda. São Paulo: Ed. 34, 2010.

PEDRON, Denise Araújo. Um olhar sobre a performatividade na cultura contemporânea: a performance como conceito e a produção artística de Diamela Eltit. 2006. 173p. Tese (Doutorado em Estudos Literários) - Faculdade de Letras, Universidade Federal de Minas Gerais, Belo Horizonte, 2006. 
RANCIÈRE, Jacques. A partilha do sensível: estética e política. Trad. Mônica Costa Netto. Rio de Janeiro: EXO experimental; Editora 34, 2005.

RANCIÈRE, Jacques. O inconsciente estético. Trad. Mônica Costa Netto. Rio de Janeiro: Editora 34, 2009.

RAVETTI, Graciela. Ficción y performance en escritores latinoamericanos contemporáneos. Diálogos Latinoamericanos, Universidad de Aarhus, n. 4, p. 47-57, 2001. Disponível em: <http://redalyc.uaemex.mx/redalyc/pdf/162/16200404.pdf>. Acesso em: 9 ago. 2006.

RAVETTI, Graciela. Narrativas performáticas. In: RAVETTI, Graciela; ARBEX, Márcia (Org.). Performance, exílio, fronteiras: errâncias territoriais e textuais. Belo Horizonte: Departamento de Letras Românicas, Faculdade de Letras/UFMG: PosLit, 2002. p. 47-68.

RAVETTI, Graciela. Nem pedra na pedra, nem ar no ar: reflexões sobre literatura latinoamericana. Belo Horizonte: Editora UFMG, 2011.

RAVETTI, Graciela. Notaciones espaciales como formas de inteligibilidad cultural: José María Arguedas, Graciliano Ramos y Juan José Saer. Caligrama, Belo Horizonte, v. 10, p. 183-208, 2005.2 Disponível em: <http://www.letras.ufmg.br/poslit/16_producao_pgs/RAVETTI_GIG.pdf>. Acesso em: 2 set. 2011.

RAVETTI, Graciela. O corpo na letra: o transgênero performático. In: CARREIRA, André et al. (Org.). Mediações performáticas latino-americanas. Belo Horizonte: FALE/UFMG, 2003a. p. 81-97.

RAVETTI, Graciela. Performances escritas: o diáfano e o opaco da experiência. In: HILDEBRANDO, Antônio; NASCIMENTO, Lylei; ROJO, Sara (Org.). O corpo em performance. Belo Horizonte: NELAP/FALE/UFMG, 2003b. p. 31-61.

RAVETTI, Graciela. Retórica performática: a catacrese do narrador no romance contemporâneo. Cadernos de Letras da UFF - Dossiê "Diálogos Interamericanos”, n. 38, p. 71-87, 2009a.

RAVETTI, Graciela. Saberes performáticos nas ficções de Haroldo Conti. Revista Gragoatá, Niterói, Universidade Federal Fluminense - UFF, n. 22, p. 163-178, 2007.

RAVETTI, Graciela. Transgênero performático e catacrese: notas para uma teoria do romance latino-americano contemporâneo. In: ROJO, Sara et. al (Org.). ANAIS DO V CONGRESSO BRASILEIRO DE HISPANISTAS E I CONGRESSO DA ASSOCIAÇÃO BRASILEIRA DE HISPANISTAS. Anais... Belo Horizonte: Faculdade de Letras da UFMG, 2009b. p. 977988.

RAVETTI, Graciela; ARBEX, Márcia (Org.). Performance, exílio, fronteiras: errâncias territoriais e textuais. Belo Horizonte: Departamento de Letras Românicas, Poslit/FALE/UFMG, 2002.

RAVETTI, Graciela; FANTINI, Marli (Org.). Olhares críticos: estudos de literatura e cultura. Belo Horizonte: Ed. UFMG, 2009.

SAER, Juan José Ninguém nada nunca. Trad. Bernardo Carvalho. São Paulo: Companhia das Letras, 1997.

SAER, Juan José. Nadie nada nunca. 2. ed. Buenos Aires: Planeta, 2000. 